\title{
Comparison of Different Anesthetic Regimens in Patients Undergoing Laparoscopic Adjustable Gastric Banding Operations: A Prospective Randomized Trial
}

\author{
Eglè Kontrimavičiūtè $\dot{e}^{1,2}$, Jūratė Šipylaitė ${ }^{1,2}$, Diana Aksionova ${ }^{1,3}$, \\ Giedrè Cincilevičiūté $\dot{e}^{4}$, Gintautas Brimas ${ }^{1,3}$ \\ ${ }^{1}$ Faculty of Medicine, Vilnius University, \\ ${ }^{2}$ Clinic of Anesthesiology and Reanimatology, Vilnius University Hospital Santariškiu Klinikos, \\ ${ }^{3}$ Clinic of Gastroenterology, Nefrourology and Surgery, Vilnius University Hospital Santariškiu Klinikos, \\ ${ }^{4}$ Department of Pulmonology and Immunology, Medical Academy, Lithuanian University of Health Sciences, Lithuania
}

Key Words: morbid obesity; laparoscopic adjustable gastric banding operation; respiratory function; remifentanil-induced hyperalgesia; reverse Trendelenburg position.

Summary. Background and Objective. Obesity is a multisystem disorder, particularly involving the respiratory and cardiovascular systems; therefore, a multidisciplinary approach is required. In spite of widespread performance of weight reduction (bariatric) surgeries, information regarding the anesthetic care of morbidly obese patients is scarce. The aim of this study was to compare the impact of fentanyl and remifentanil on the time of recovery, breathing parameters, and postoperative pain in morbidly obese patients undergoing laparoscopic adjustable gastric banding operations.

Material and Methods. In this prospective randomized study, 66 morbidly obese patients $\left(B M I>35 \mathrm{~kg} / \mathrm{m}^{2}\right)$, aged between 24 and 70 years, scheduled for a laparoscopic adjustable gastric banding operation were divided into 2 groups based on the opioid used for anesthesia: group 1 whose who received remifentanil; and group 2, fentanyl). The following parameters were recorded: peripheral blood oxygenation ( $\mathrm{SpO}_{2}$ ) while breathing room air at baseline and 5 minutes after preoxygenation (100\%); end-tidal carbon dioxide pressure at designated time points during the procedure; time to extubation; $\mathrm{SpO}_{2}$ in the postanesthesia care unit; and pain intensity (using the visual analogue scale); and the presence of nausea and vomiting.

Results. The time to extubation was shorter in the remifentanil group, but there was no significant difference in the time to discharge from the postanesthesia care unit. The recovery of respiratory parameters to the baseline values was better and faster in the remifentanil group. The intensity of postoperative pain was similar in both groups $(V A S,<3)$

Conclusions. Remifentanil showed good analgesic properties during laparoscopic gastric banding surgery. Postanesthesia recovery and return of respiratory parameters to the baseline values was faster when remifentanil was used. Postoperative pain and the rate of opioid-induced side effects after analgesia with remifentanil were similar as after anesthesia with a longer acting opioid, fentanyl. Despite the problem widely discussed in literature about remifentanil-induced hyperalgesia, no cases of analgesic overconsumption were registered in our study.

\section{Introduction}

The prevalence of morbid obesity is increasing worldwide, and surgical interventions may entail a considerable risk for obese patients. Obesity is a multisystem disorder, particularly involving the respiratory and cardiovascular systems; therefore, a multidisciplinary approach is required. In spite of widespread performance of weight reduction (bariatric) surgeries, information on the anesthetic care of morbidly obese patients is scarce.

Correspondence to E. Kontrimavičiūtè, Clinic of Anesthesiology and Reanimatology, Vilnius University Hospital Santariškių Klinikos, Santariškių 2, 08661 Vilnius, Lithuania

E-mail: egle.kontrimaviciute@santa.lt
One of many problems in the anesthetic management of morbidly obese patients (body mass index [BMI], $\left.>35 \mathrm{~kg} / \mathrm{m}^{2}\right)$ is the maintenance of adequate oxygenation. Anesthesia adversely affects the respiratory function and leads to a reduced functional residual capacity (FRC). In obese patients, FRC markedly decreases with possible hypoxemia and hypercapnia during the postoperative period (1-3). The body weight is a primary factor determining arterial oxygen tension although pneumoperitoneum and position changes (Trendelenburg and reverse Trendelenburg) do not significantly alter oxygenation despite considerable deterioration in the respiratory system mechanics (3). 
Postoperative awakening and rapid recovery of spontaneous respiratory parameters depend on the agents used for anesthesia. Several studies have evaluated the benefits of the use of poorly soluble volatile anesthetic agents (desflurane and sevoflurane) in comparison with more soluble ones (isoflurane) or propofol in morbidly obese patients $(4,5)$. Opioids used for general anesthesia in the obese patients during laparoscopic operations vary, but ultrashortacting opioids, such as remifentanil and sufentanil, are considered the opioids of choice (6). Otherwise, remifentanil-induced hyperalgesia, especially when high doses of remifentanil are infused, is also a matter of concern and remains a controversy $(7,8)$.

Because awake morbidly obese patients already have severe alterations of their respiratory mechanics (decreased chest wall and lung compliances and decreased FRC), we hypothesized that the choice of anesthetic agents would be associated with better recovery.

The aim of this prospective, randomized study was to compare the impact of fentanyl and remifentanil on the time of recovery, breathing parameters, and postoperative pain in morbidly obese patients undergoing laparoscopic adjustable gastric banding operations.

\section{Material and Methods}

The study protocol was approved on November 6, 2008 (No. 62), by the Lithuanian Bioethics Committee and the Faculty of Medicine, Vilnius University.

After written informed consent was obtained, morbidly obese patients (BMI, $>35 \mathrm{~kg} / \mathrm{m}^{2}$ ) aged between 24 and 70 years, the American Society of Anesthesiologists (ASA) status class 2 and 3, and scheduled for a laparoscopic adjustable gastric banding operation (LAGB, MiniMizer extra, port medium) were included in the study. The exclusion criteria were difficult airways, obstructive pulmonary disease, ischemic heart disease, known impaired renal or hepatic function, and neuromuscular disorders.

During the preoperative visit, an anesthesiologist carried out airway assessment and laryngoscopy grading according to the Mallampati classification. The patients were classified to the following classes: class, 1 the tonsils, uvula, and soft palate are clearly visible; class 2 , the hard and soft palates, upper portion of tonsils, and uvula are visible; class 3 , the soft and hard palates and the base of the uvula are visible; and class 4 , only the hard palate is visible.

The patients were grouped using a set of computer-generated random numbers kept in sequentially numbered opaque sealed envelopes. All the patients received premedication $(7.5 \mathrm{mg}$ of midazolam per os at night).
On arrival to the operating room, 3-lead electrocardiography, a noninvasive measurement of blood pressure, and pulse oximetry were performed. After 5 minutes of preoxygenation with 100\% oxygen, general anesthesia was induced with remifentanil ( $1 \mu \mathrm{g} / \mathrm{kg}$ of total body weight, TBW) during the first 45 seconds followed by an infusion of $0.1-$ $0.15-0.2 \mu \mathrm{g} /(\mathrm{kg} \cdot \mathrm{min})$ of TBW (remifentanil group) or intravenous fentanyl at a dose of $500 \mu \mathrm{g}$ (fentanyl group). The remifentanil infusion rate was titrated to patients' responses. All the patients received thiopental $(4 \mathrm{mg} / \mathrm{kg})$, and tracheal intubation was facilitated with succinylcholine $(1.5 \mathrm{mg} / \mathrm{kg})(9)$. The endotracheal tube size depended on the patient's gender, i.e., female patients were intubated with size 7.5 ID, male patients with 8.5 ID. None of the patients required fiberoptic intubation. The presence of a capnography trace and bilateral breath sounds were confirmed by an anesthesiologist who performed the intubation. Anesthesia was maintained with Sevorane in a mixture of oxygen and air adjusted to maintain inspiratory $\mathrm{O}_{2}$ at $70 \%$. The mechanical ventilation was conducted with a semiclosed circuitbreathing device Dräger (tidal volume, $10 \mathrm{mg} / \mathrm{kg}$; respiratory rate, $12-14$ breaths per minute; positive end-expiratory pressure, $4 \mathrm{~cm} \mathrm{H}_{2} \mathrm{O}$ ) to maintain the end-tidal carbon dioxide pressure $\left(\mathrm{P}_{\mathrm{ET}} \mathrm{CO}_{2}\right)$ between 30 and $35 \mathrm{~mm} \mathrm{Hg}$. The neuromuscular blockade was maintained with rocuronium $(0.6 \mathrm{mg} / \mathrm{kg}$ ideal body weight, IBW $=$ height in $\mathrm{cm}-106$ [for women] or 102 [for men]) (10).

After the intubation, all the patients received intramuscular diclofenac $(75 \mathrm{mg})$ and intravenous dexamethasone $(8 \mathrm{mg})$. Sevorane was maintained up to 0.8-1.2 minimum alveolar concentration, which was adjusted to keep hemodynamic changes within $20 \%$ of the baseline values measured during the preoperative anesthetic visit. The patients' lungs were ventilated with air and oxygen $\left(\mathrm{FIO}_{2}, 0.6\right)$; the initial ventilatory setting was set at the frequency of 12-14 breaths per minute, the inspiratory-toexpiratory ratio of $1: 2$, positive end-expiratory pressure (PEEP) of $4 \mathrm{~cm} \mathrm{H}_{2} \mathrm{O}$, and tidal volume of $600-700 \mathrm{~mL}(8 \mathrm{~mL} / \mathrm{kg})$ (Dräger Ohmeda $\mathrm{S} / 5$ Avance). Muscle relaxation was monitored in the train-of-four values on the radial nerve; decurarization at the end of surgery was considered if the TOF values were $0.7-0.8$. Entropy-based method was used to monitor the depth of anesthesia with the values kept at 50-55. Then the patient was positioned in the semisitting reverse Trendelenburg position during the entire laparoscopic procedure (pneumoperitoneum pressure was kept at $16 \mathrm{~mm} \mathrm{Hg}$ ) with spread legs and stretched arms. All the patients in both groups received intravenous morphine at a total dose of $10 \mathrm{mg} \mathrm{30-50} \mathrm{minutes}$ before the end of the surgery. 
The following parameters were recorded: peripheral blood oxygen saturation $\left(\mathrm{SpO}_{2}\right)$ while breathing room air after 5 minutes of preoxygenation with $100 \%$ oxygen via a face mask and $\mathrm{P}_{\mathrm{ET}} \mathrm{CO}_{2}$. Muscle fasciculations due to the administration of depolarizing muscle relaxant succinylcholine were registered, and their severity was evaluated as well: no fasciculations, moderate fasciculations, and severe fasciculations. All the measurements were performed at designated time points during the procedure. The parameters of both the groups were recorded at the following time points: immediately after the intubation; 5 minutes after the intubation; at the moment when the patient's position was changed into the reverse Trendelenburg position and $\mathrm{CO}_{2}$ insufflation was initiated; 5 minutes after the patients' position was changed into the reverse Trendelenburg position; at the time when the patient's initial position was resumed (end of the laparoscopic period of the operation); and 5 minutes after placing the patient into a neutral position.

The infusion of remifentanil in the group 1 was discontinued when the wound was started to suture, and sevoflurane was discontinued with the last suture in both the groups. When adequate spontaneous respiration returned and verbal contact was initiated, the patients were extubated in the operating room. Then the patients were transferred to a postanesthesia care unit (PACU), they were placed in the semisitting position, and the facial mask with $5 \mathrm{~L}$ of oxygen per minute was applied for 1 to 1.5 hours.

In the PACU setting, $\mathrm{SpO}_{2}$, pain according to the visual analogue scale (VAS), and presence of nausea and vomiting were evaluated. Pain control was considered adequate if the score on the VAS was 3 and less. Rescue analgesia was maintained with intravenous morphine.

Other data recorded were the duration of anesthesia (time between induction and extubation), duration of surgery (time between incision and skin closure), additional analgesic agents in the PACU, nausea/vomiting in the PACU, time to discharge, and $\mathrm{SpO}_{2}$ on discharge from the PACU.

Statistical data analysis was carried out using the Statistical Package for Social Sciences (SPSS) for Windows, version 17. The intergroup differences were analyzed using the Student $t$ test. To investigate the correlation between the used opioid, BMI, extubation time, and the respiratory parameters during the surgery, the Pearson correlation analysis was performed. A value of $P$ less than 0.05 was considered statistically significant.

It was hypothesized that recovery would be faster in the group 1 than group 2 . Therefore, the primary end-point was the time spent by the patients in the PACU. Based on the previous data from our group, it was calculated that the length of stay of $120 \pm 20$ minutes and a difference between the groups of 30 minutes could be considered clinically relevant. For a power of 0.9 and assuming $\alpha$ risk of 0.05 , the sample size of 30 patients in each group was calculated to be appropriate.

\section{Results}

Altogether, 72 patients were screened during the study period from January 2009 to December 2009. The patients were assigned to either the remifentanil group (group 1) or the fentanyl group (group 2). However, 6 patients did not meet the inclusion criteria: 4 patients were excluded because of obstructive pulmonary disease (1 patient in the group 1), and 2 patients had a history of difficult intubation (group 2). All the patients underwent the procedures uneventfully. The demographic and clinical data of the enrolled patients are presented in Table 1. There were no significant differences in the demographic data, except for age, duration of the operation or anesthesia, and $\mathrm{SpO}_{2}$ on arrival between the groups. Hemodynamic parameters during the operation were similar in both groups (data not shown).

Table 2 shows the distribution of patients according to the Mallampati classification assessed during the preoperative visit by an anesthesiologist and severity of fasciculations. Succinylcholine was used in all the cases to facilitate tracheal intubation, and fasciculations due to the use of succinylcholine were

Table 1. Demographic and Clinical Data

\begin{tabular}{lccc}
\hline \multicolumn{1}{c}{ Parameter } & $\begin{array}{c}\text { Remifentanil Group } \\
\text { (Group 1) } \\
n=26\end{array}$ & $\begin{array}{c}\text { Fentanyl Group } \\
\text { (Group 2) } \\
\text { n=40 }\end{array}$ & $P$ \\
\hline Age, years & $41.6(10.0)[24-67]$ & $48.3(12.9)[26-70]$ & 0.02 \\
Sex, male/female, $\mathrm{n}$ & $8 / 18$ & $44 / 26$ & 0.59 \\
$\mathrm{BMI}, \mathrm{kg} / \mathrm{m}^{2}$ & $45.9(6.9)[35-61]$ & $68.3(7.0)[35-67]$ & 0.19 \\
Duration of surgery, min & $69.8(16.5)[45-130]$ & $99.9(18.8)[40-125]$ & 0.9 \\
Duration of anesthesia, min & $90(19.5)[50-150]$ & $95.1(2.3)[65-155]$ & 0.06 \\
$\mathrm{SpO}_{2}$ on arrival, \% & $95.8(2.3)[90-100]$ & $0.99]$ & 0.25 \\
\hline
\end{tabular}

Values are mean (SD) [range] unless otherwise noted. 
Table 2. Distribution of Patients According to the Mallampati Classification and Severity of Fasciculations

\begin{tabular}{ccc}
\hline Variable & $\begin{array}{c}\text { Remifentanil Group } \\
\text { (Group 1) } \\
\mathrm{n}=26\end{array}$ & $\begin{array}{c}\text { Fentanyl Group } \\
\text { (Group 2) } \\
\mathrm{n}=40\end{array}$ \\
\hline Mallampati class & & \\
1 & $2(7.7)$ & $2(5.0)$ \\
2 & $10(38.5)$ & $9(22.5)$ \\
3 & $10(38.5)$ & $13(32.5)$ \\
4 & $4(15.4)$ & $16(40)$ \\
\hline Fasciculation & & \\
Absent & $13(50.0)$ & $18(22.2)$ \\
Moderate & $11(42.3)$ & $20(20.0)$ \\
Severe & $2(7.7)$ & $2(5.0)$ \\
\hline
\end{tabular}

Values are number (percentage).

registered. There were only a few cases of failed intubation in both the groups: 2 patients in the group 1 were intubated from the third attempt, 1 patient and 2 patients in the group 2 were intubated from the second and third attempts, respectively. There was no significant difference comparing the severity of fasciculations between the groups $(P=0.8)$.

Respiratory parameters were monitored during the operation and were registered at 6 different time points. Fig. 1 represents the change in $\mathrm{P}_{\mathrm{ET}} \mathrm{CO}_{2}$ during the operation at the particular time points. No significant differences were registered comparing the groups. Among the morbidly obese patients, there was a correlation between $\mathrm{BMI}$ and $\mathrm{P}_{\mathrm{ET}} \mathrm{CO}_{2}$ when the patients were placed in the reverse Trendelenburg position $(r=0.264, P=0.018)$ (Fig. 2$)$ and after 5 minutes ( $r=0.378, P=0.03)$.

According to the protocol, all the patients spent 120 minutes in the PACU and were discharged. Before the discharge, the patients were breathing room air for at least 20 minutes. $\mathrm{SpO}_{2}$ was registered on discharge, and any complaints of breathing shortage were taken into account. There were no patients in both the groups who needed extra time to spend in the PACU (Table 3).

Peripheral blood oxygenation while breathing room air was registered on patients' arrival to the operating room and on discharge. There was no significant correlation between $\mathrm{BMI}$ and $\mathrm{SpO}$, on arrival ( $r=-0.337, P=0.25$ ), but on discharge, BMI and $\mathrm{SpO}_{2}$ were significantly correlated $(r=-0.269$, $P=0.016)^{2}$ (Fig. 3).

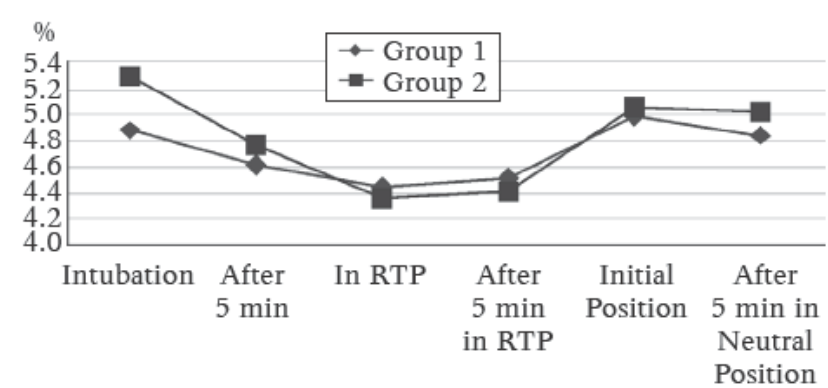

Fig. 1. Intraoperative changes in the end-tidal carbon dioxide pressure $\left(\mathrm{P}_{\mathrm{ET}} \mathrm{CO}_{2}\right)$

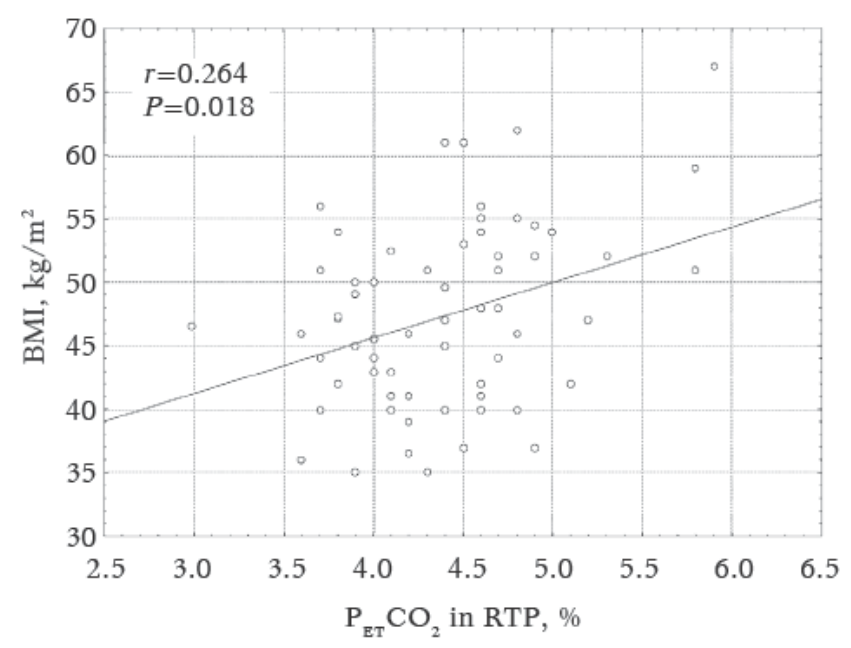

Fig. 2. Correlation between body mass index (BMI) and end-tidal carbon dioxide pressure $\left(\mathrm{P}_{\mathrm{ET}} \mathrm{CO}_{2}\right)$ in the reverse Trendelenburg position (RTP)

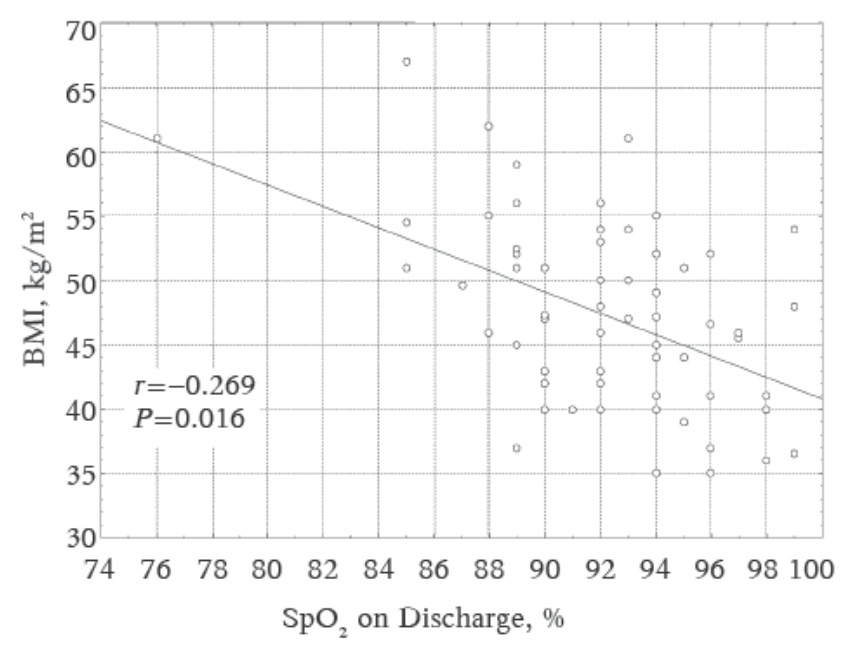

Fig. 3. Correlation between body mass index (BMI) and peripheral blood oxygen saturation $\left(\mathrm{SpO}_{2}\right)$ on discharge

Table 3. Postoperative Data: Time to Extubation, Additional Analgesic Consumption, and Nausea/Vomiting in the Postanesthesia Care Unit

\begin{tabular}{lccc}
\hline \multicolumn{1}{c}{ Parameter } & $\begin{array}{c}\text { Remifentanil Group } \\
\text { (Group 1) } \\
\mathrm{n}=26\end{array}$ & $\begin{array}{c}\text { Fentanyl Group } \\
\text { (Group 2) } \\
\mathrm{n}=40\end{array}$ & $P$ \\
\hline Time to extubation, min & $6.5(3.4)[5-20]$ & $14.3(7.6[5-30]$ & 0.001 \\
Additional analgetic (morphine), mg & $12.1(4.7)[10-25]$ & $10.5(2.5)[5-20]$ & 0.12 \\
Nausea/vomiting in the PACU, $\mathrm{n}(\%)$ & $2(7.6)$ & $4(10)$ & 0.19 \\
SpO, on discharge, \% & $94.1(3.1)[88-99]$ & $90.9(4.0)[82-99]$ & 0.00045 \\
\hline
\end{tabular}

Values are mean (SD) (range) unless otherwise noted. PACU, Postanesthesia Care Unit; $\mathrm{SpO}_{2}$, peripheral blood oxygen saturation. 
On arrival, there was no difference in $\mathrm{SpO}_{2}$ between the groups $(P=0.7)$, but on discharge, the group 1 showed significantly better $\mathrm{SpO}_{2}$ values than the group $2(P<0.00045)$. The patients receiving remifentanil (group 1) showed significantly faster recovery after the operation and a shorter time to extubation, but the opioid (remifentanil or fentanyl) used for analgesia during the operation had no impact on the patients' stay time in the PACU.

\section{Discussion}

The results of this study indicated that the time to extubation was shorter in the remifentanil group, but the time to discharge from the PACU after laparoscopic adjustable gastric banding operations was not influenced by the choice of the opioid administered during the operation. The length of stay in the PACU was similar in both groups, and the return of respiratory parameters to the preoperative values was better and faster in the remifentanil group. Postoperative pain according to the VAS was similar in both the groups.

Succinylcholine was used to facilitate tracheal intubation for its rapid onset of action and short duration of action because in morbidly obese patients, hemoglobin desaturation occurs rapidly after apnea, and the intubation of trachea must be accomplished quickly (9). The evaluation of morbidly obese patients according to the Mallampati classification loses its value in predicting the difficulty of forthcoming tracheal intubation; 23 and 20 patients were classified as Mallampati class 3 and 4, respectively, but only 2 patients classified as Mallampati class 3 and 4 were intubated after repeated attempts, the same as 2 patients classified as Mallampati class 1 and 2.

The present study considered the postoperative recovery time, time to extubation, postoperative pain, and episodes of postoperative nausea and vomiting. Postoperative pain according to the VAS in the PACU was similar. Morphine as a rescue analgesic was used in both the groups, and although greater usage was documented in the remifentanil group, the difference between the groups was insignificant. Besides, a laparoscopic gastric banding operation is not considered a particularly painful procedure. In addition, nonsteroidal anti-inflammatory therapy (Diclac, $75 \mathrm{mg}$ intravenously) was initiated during the anesthesia.

In morbidly obese patients, alfentanil, fentanyl, and remifentanil can be safely used, but a study by Gaszynski et al. reported a higher frequency of postoperative nausea and vomiting and more severe postoperative pain in the remifentanil group (11). The reason for a larger discrepancy in the postoperative need of a rescue analgesic between remifentanil and other opioids is unknown. However, there are several possible explanations: pa- tients receiving remifentanil develop acute opioid tolerance while other opioids have longer acting postoperative residual effects, or remifentanil causes hyperalgesia (12). Moreover, the evidence of dose-dependent hyperalgesia exists, and a number of articles describe additional options how to solve this problem $(13,14)$. Additives, such as magnesium sulfate, ketamine, or dexmetomedine, can decrease the pain threshold at the peri-incisional areas $(13,14)$, but ketamine may cause other wellknown problems like hallucinations and an altered body image in the early postoperative period. Besides, the infusion dose of remifentanil also matters: the higher the individual requirements are, the higher the risk of postoperative hyperalgesia appears because acute opioid tolerance seems to be dose dependant (15).

Respiratory mechanics in healthy, normalweight, nonanesthetized patients changes minimally over a wide range of postures, including both $30^{\circ}$ head-up and head-down positions. In healthy nonobese patients, abdominal insufflation in the headdown position only moderately decreases the respiratory system compliance. Morbid obesity itself may cause a significant respiratory system alteration (16-18). The respiratory system compliance exponentially decreases as a function of the increased body mass index (2). A reduced lung volume can explain the alterations of respiratory system mechanics (decreased compliance and increased resistance) in anesthetized morbidly obese patients in the supine position. Induction of $16-\mathrm{mm} \mathrm{Hg} \mathrm{CO}_{2}$ pneumoperitoneum and positioning of these patients in the reverse Trendelenburg posture (beach chair position) reduced the respiratory compliance and increased the resistance (19). Similar studies revealed a correlation between body mass index and inspiratory resistance in the presence of pneumoperitoneum while performing laparoscopic operations in the reverse Trendelenburg position (2). The hypothesis that the reverse Trendelenburg position will improve respiratory mechanics because of gravitational effects on abdominal contents has been proven, but only in case of open bariatric surgery. In case of laparoscopic adjustable gastric banding operations with $\mathrm{CO}_{2}$ insufflation, the reverse Trendelenburg position had no beneficial effect on respiratory parameters, and our findings are in agreement with other studies (20).

Some limitations of our study should be mentioned. The study had to include 80 patients had a strict time to be completed. Unfortunately, in 2009, there were problems with the delivery of remifentanil, and this led to the different sample sizes in the groups. Despite this, our study succeeded to highlight some substantial differences between the patients receiving remifentanil and those receiving fentanyl. 


\section{Conclusions}

Remifentanil showed good analgesic properties during laparoscopic gastric banding surgery. Postanesthesia recovery and return of respiratory parameters to the baseline values was faster when remifentanil was used. Postoperative pain and the rate of opioid-induced side effects after analgesia with remifentanil were similar as after anesthe-

\section{References}

1. Dumont L, Mattis M, Mardirosoff C, Vervloesem N, Allé JL, Massaut J. Changes in pulmonary mechanics during laparoscopic gastroplasty in morbidly obese patients. Acta Anesthesiol Scand 1997;41:408-13.

2. Pelosi P, Croci M, Ravagnan I, Tredici S, Pedoto A, Lissoni A, et al. The effects of body mass on lung volumes, respiratory mechanics, and gas exchange during general anesthesia. Anesth Analg 1998;87:654-60.

3. Sprung J, Whalley DG, Falcone T, Warner DO, Hubmayr $\mathrm{RD}$, Hammel J. The impact of morbid obesity, pneumoperitoneum and posture on respiratory system mechanics and oxygenation during laparoscopy. Anesth Analg 2002; 94:1345-50.

4. Arain SR, Barth CD, Shankar H, Ebert TJ. Choice of volatile anesthetic in the morbidly obese patient: sevoflurane or deslurane. J Clin Anesth 2005;17:413-9.

5. Larsen B, Seitz A, Larsen R. Recovery of cognitive function after remifentanil-propofol anesthesia: a comparison with desflurane and sevoflurane anesthesia. Anesth Analg 2000;90:168-74.

6. Song D, Whitten CW, White PF. Remifentanil infusion facilitates early recovery for obese outpatients undergoing laparoscopic cholecystectomy. Anesth Analg 2000;90:1111-3.

7. Ozkose Z, Yalcin Cok O, Tuncer B, Tufekcioglu S, Yardim S. Comparison of hemodynamics, recovery profile and early postoperative pain and costs of remifentanil versus afentanil-based total intravenous anesthesia (TIVA). J Clin Anesth 2002;14:161-8.

8. Derrode N, Lebrun F, Levron JC, Chauvin M, Debaene B. Influence of perioperative opioid on postoperative pain after major abdominal surgery: sufentanil TCI versus remifentanil TCI. A randomized, controlled study. Br J Anesth 2003;91:842-9.

9. Lemmens JM, Brodsky JB. The dose of succinylcholine in morbid obesity. Anesth Analg 2006;102:438-42.

10. Meyhoff CS, Lund J, Jenstrup MT, Claudius C, Sørensen AM, Viby-Mogensen J, et al. Should dosing of rocuronium in obese patients be based on ideal or corrected body weight? Anesth Analg 2009;109:787-92.

11. Gaszynski TM, Stzelczyk JM, Gaszynski WP. Postanesthe- sia with a longer acting opioid, fentanyl. Despite the problem widely discussed in literature about remifentanil-induced hyperalgesia, no cases of analgesic overconsumption were registered in our study.

\section{Statement of Conflict of Interest}

The authors state no conflict of interest.

sia recovery after infusion of propofol with remifentanil or afentanil or fentanyl in morbidly obese patients. Obes Surg 2004;14:498-504.

12. Angst MS, Koppert W, Pahl I, Clark DI, Schmelz M. Shortterm infusion of the mu-opioid agonist remifentanil in humans causes hyperalgesia during withdrawal. Pain 2003; 106:49-57.

13. Song JW, Lee YW, Yoon KBY, Park SI, Shim YH. Magnesium sulfate prevents remifentanil-induced postoperative hyperalgesia in patients undergoing thyroidectomy. Anesth Analg 2011;113:390-7.

14. Joly V, Richebe P, Guignard B, Fletcher D, Maurette S, Sessler DI, et al. Remifentanil-induced hyperalgesia and its prevention with small-dose ketamine. Anesthesiol 2005; 130(1):147-55.

15. Guignard B, Bossard AE, Coste C, Sessler DI, Lebrault C, Alfonsi P, et al. Acute opioid tolerance: intraoperative remifentanil increases postoperative pain and morphine requirement. Anesthesiology 2000;93:409-17.

16. Barnas GM, Green MD, Mackenzie CF, Fletcher SI, Campbell DN, Runcie C, et al. Effect of posture on lung and regional chest wall mechanics. Anesthesiology 1993;78:2519 .

17. Puri GD, Singh H. Ventilatory effects of laparoscopy under general anesthesia. Br J Anaesth 1992;68:211-3.

18. Perilli V, Sollazzi L, Bozza P, Modesti C, Chierichini A, Tacchino RM, et al. The effects of reverse Trendelenburg position on respiratory mechanics and blood gases in morbidly obese patients during bariatric surgery. Anesth Analg 2000;91:1520-5.

19. Sprung J, Whalley DG, Falcone T, Warner DO, Hubmayr $\mathrm{RD}$, Hammel J. The impact of morbid obesity, pneumoperitoneum, and posture on respiratory system mechanics and oxygenation during laparoscopy. Anesth Analg 2002;84:1345-50.

20. Pelosi A, Commotti L, Tomassino C, Leggieri C, Bignami E, Tarantino F, et al. Effects of pneumoperitoneum and reverse Trendelenburg position on cardiopulmonary function in morbidly obese patients receiving laparoscopic gastric banding. Eur J Anaesthesiol 2000;17:300-5. 